\title{
Environmental impact of printing inks and printing process
}

\begin{abstract}
In the Printing Industry, printing inks, varnishes, lacquers, moistening solutions and washing solvents (ethanol, methyl acetate, ethyl acetate, isopropanol, n-propanol, hexane, benzene, toluene, xylene, isopropyl acetate, propyl acetate, dimethyl ketone, glycols and glycol ethers) contain volatile organic compounds (VOCs) and air pollutants (HAPs). Especially solvent based inks used for flexo, gravure and screen printing, offset printing dampening solutions and cleaning solvents contain high concentration of VOC. These organic compounds evaporate during the production process or contribute to the photochemical reaction. VOCs and HAPs, together with sunlight and nitrogen oxides, cause photochemical smoke, air particles and ground level ozone emission in the atmosphere. The VOCs and heavy metals can lead to soil and even water pollution when left in landfill. The amount of solvent retained by flexo, gravure and screen-printed products is 3-4\% of total ink solvent used. The solvent in the printed ink content, except for the one held by the printed material evaporates in its own environment after the printing process. Most of these solvents and organic compounds used in printing environment contain at least one carbon and hydrogen atom and have negative effects on health and environment.In this study, the environmental impacts and risks of inks and solvents used in the printing industry have been evaluated. Measures to be taken to reduce and manage these environmental effects and risks have been addressed and recommendations have been made.
\end{abstract}

\author{
Cem Aydemir ${ }^{1}$ (1) \\ Samed Ayhan Özsoy² \\ ${ }^{1}$ Marmara University, School of \\ Applied Science, Department of \\ Printing Technologies, \\ Istanbul, Turkey \\ ${ }^{2}$ Istanbul University Cerrahpasa, \\ Vocational School of Technical \\ Sciences, Printing and Publication \\ Technologies Program, \\ Istanbul, Turkey \\ Corresponding author: \\ Cem Aydemir \\ e-mail: \\ cemaydemir@marmara.edu.tr
}

First recieved: 04.04.2020.

Accepted: 04.05.2020.

\section{KEY WORDS}

Printing industry, volatile organic compounds, air pollutants,

environmental impact

\section{Introduction}

Solvents may be defined as complicated chemical mixtures containing several different types of hydrocarbon such as small aerosolisable aromatic molecules and vaporizing as VOCs and as alkanes, alcohols, ketones, aldehydes, esters, ethers (Viegas, 2011). In almost every production industry the solvent is used in the processes such as degreasing, cleaning and etc. There are two different types of solvents as halogenated and halogen-free. They may have the characteristic of a 'hazardous chemical' according to the feature of the chemical materials they contain and may also have the feature of hazardous waste at the end of its use. Halogen-free solvents are aliphatic and aromatic hydrocarbon compounds. Methyl-chloride, ethyl chloride, trichloroethanol, chloroform, chloroethane compounds, chlorinated benzines and chlorinated phenol compounds could be 
given as examples of halogenated solvents. The chemical compounds containing at least one carbon and a hydrogen atom are called "organic compounds". Organic compounds are examined under three main groups (Table 1) as very volatile organic compounds (VVOCs) volatile organic compounds (VOCs) and semi-volatile inorganic compounds (SVOCs). These compounds cause soil pollution, underground water pollution, environment pollution and air pollution (US EPA, 2018).

\section{Table 1}

Classification of Organic Pollutants (Okubo \& Kuwahara, 2020)

\begin{tabular}{l|l|l}
\hline $\begin{array}{l}\text { Chemicals } \\
\text { group }\end{array}$ & Boiling point ('C) $^{\circ}$ & Organic chemicals \\
\hline VVOCs & $<0$ to 50-100 & $\begin{array}{l}\text { Propane, methane, } \\
\text { formaldehyde, } \\
\text { acetaldehyde, } \\
\text { dichloromethane, } \\
\text { butane, methyl } \\
\text { chloride, etc. }\end{array}$ \\
\hline VOCs & $50-100$ to 240-260 & $\begin{array}{l}\text { Ethyl alcohol, acetone, } \\
\text { benzene, toluene, } \\
\text { xylene, isopropyl } \\
\text { alcohol, hexanal, etc. }\end{array}$ \\
\hline SVOCs & $240-260$ to 380-400 & $\begin{array}{l}\text { Chlorpyrifos, } \\
\text { dibutyl phthalate, } \\
\text { bis (2-ethylhexyl) } \\
\text { phthalate, pesticides } \\
\text { (DDT, chlordane, } \\
\text { plasticizers), etc. }\end{array}$ \\
\hline
\end{tabular}

VOCs released to the environment from solids and liquids in gas form (Khan \& Ghoshal, 2000). Vapourphase organic compounds are very important for the control in air pollution due to the direct and secondary environmental effects. VOCs are of concern as both indoor air pollutants and as outdoor air pollutants. However, the emphasis of that concern outdoors is different from indoors. The main concern indoors is the potential for VOCs to adversely impact the health of people that are exposed (US EPA, 2018). Some of these compounds contain several chemicals which may have short-term and long-term negative health effects, and their impact on human health becomes much more severe in indoor spaces (Rösch et al., 2014). The existence of these indoor air pollutants increases the risk of people with breathing problems, such as asthma sufferers, and with compromised or underdeveloped immune systems (Leung, 2015).

Ink always comes to mind as the latest when the health of living things and the environment are considered. In fact, printed products surround people in every stage of life. We come across with printed products everywhere as daily newspapers, books and packaged products. The printing of the materials such as newspapers, magazines, books, catalogues, packages, prospectus, leaflets, advertising supplements, flyers, calendars, company directives, posters and publicity posters has been increasing every passing day. There is a need for energy, paper and ink in order to produce these materials (Blue Angel, 2020).

Printing inks, overprint varnishes and lacquers, additives, diluting solvents, cleaning solutions and wash-up materials, dampening solvents, glues and adhesives used in packaging systems may have a potential effect on the environment at certain points during their own usage cycle (Khan \& Ghoshal, 2000; Svendsen \& Rognes, 2000) have stated that most important factor of solvent material exposure in offset printing is the humidifier used in printing machines. VOCs should be addressed at this point. VOCs cause greenhouse effect and ozone in the sub-atmosphere (US EPA, 2018). For this reason, it is associated with global warming (Aydemir, Yenidoğan \& Özsoy, 2020).

Organic solvent-based flexo including organic solutions, gravure, digital and screen-printing inks, oilbased heat-set web offset inks and solvent compounds used in printing surface coating and solvents added for dilution are the sources of VOC emissions. VOC emissions can occur in any processes of ink mixing, printing, surface coating and storing (IFC, 2007). In other words, it means the organic solvents and diluents are released to the atmosphere during printing process (Figure 1). Moreover, printing inks, solvent based cleansers used in machine cleansing process also cause the release of ozone and volatile organic compounds contributing to the air pollution (Blue Angel, 2020).

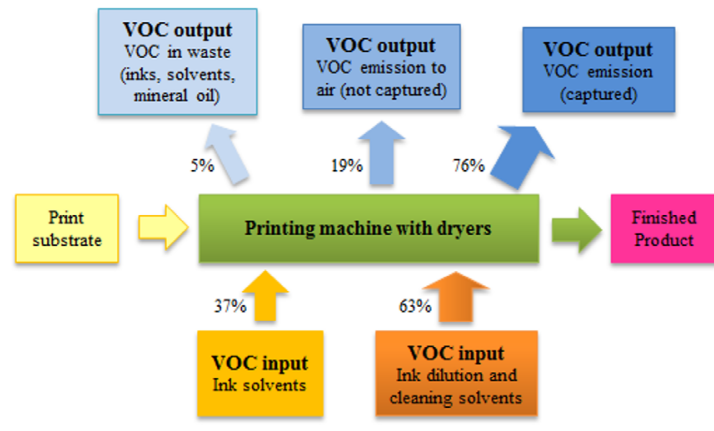

» Figure 1: VOC input and output during the printing process

As the environmental awareness increased globally, the demand for the ink made of renewable resources with low carbon footprint has also been increasing (Aydemir et al., 2018). In the ink systems, water began to replace the solvent and vegetable began to replace mineral oil (Robert, 2015). Using water and vegetable oil instead of evaporative chemical solvents in the ink systems, enables the VOCs to be reduced during printing process (Sensorex, 2017). Replacing water with the solvent in the ink, seems environmentally beneficial. However, four times more power is required in order to evaporate the same amount of water in the ink (Aydemir \& Özakhun, 2014). This situation may cause high carbon footprint (EuPIA, 
2013). Thus, substrates with high absorbing capacity requiring low drying energy should be preferred for the prints performed with water-based ink. The absorption, wettability and surface energy of the substrate should be well-known (Aydemir et al., 2019). During the industrial printing processes, optimization of energy use is extremely important in terms of environment. In order to evaluate the environmental impact of each ink and printing technique, it is necessary to make a Life Cycle Assessment that considers the raw material, manufacturing, distribution, use, and final disposal (Hermann, 2014).

In recent years, the number of studies focusing on the reduction of VOCs content produced by inks has boosted due to increased environmental awareness (Aydemir, Yenidoğan \& Özsoy, 2020). In this study, the effects of inks and solvents on the environment have been evaluated and recommendations for the elimination of such effects have been given.

\section{Solvent Emissions Directive and the Control of VOC Emissions}

The emissions result from evaporation of VOC and HAP contained in the inks during the printing process. The fact that vaporized solvents damages the ozone layer seriously according to the studies, leads the countries to take measures. Thus, it is inevitable for printing industry to carry out regulations about VOC and HAP having negative effects on the environment (Khan \& Ghoshal, 2000). The Environmental Protection Agencies in US, Europe, Canada, and many other countries have restricted the amount of solvent that can be released into the air to reduce the pollutants released to the environment by the printing industry (Saad, 2007).

The emissions of VOCs should be controlled within the limits under the EU Solvent Emissions Directive (EuPIA, 2013). The purpose of this directive is to limit the total content of VOC in certain dyes, inks and varnishes in order to reduce and prevent the air and environment pollution (US EPA, 2018). Emission is controlled by recovery such as adsorption (scrubbing), desorption, condensation and traditional systems of abatement such as catalytic thermal oxidation, thermal oxidation and biological scrubbing (Inglezakis \& Poulopoulos, 2006). In large-scale flexographic and gravure printing processes, thermal oxidation is the most common (EuPIA, 2013).

\section{The Environmental Impacts of Pre-Press Processes}

Although no significant VOC emissions are generated from the prepress / imaging process, developers and fixers may generate emissions of sulphur compounds, acetic acid, and ammonia from blueprint, as well as odours, particularly in older processes (IFC, 2007).

Computer-to-plate technology (CTP) increased the efficiency of pre-press processes in all printing systems and reduced the use of water significantly. Moreover, other chemicals such as photographic film and photographic developer containing silver and print developer were not used. Thus, the factors having negative effect on the environment due to the waste film, waste developer and water consumption and causing waste formation were eliminated. Using metal by engraving instead of using acid in preparation print developer for gravure printing, is one of the important measures minimizing the environmental impact of pre-press processes.

\section{Solvent Impacts in Printing Environment}

Printing environment is usually the major source of emission due to the storage, usage and final disposal of chemicals and liquid waste. Most common emissions caused by printing process are gases and emissions of VOC caused by process chemicals and cleaning solvents. VOCs such as xylenes, ketones, alcohols and aliphatic are available in printing inks, dampening water solutions and cleaning solvents. The solvents used in cleansing of printing plates, blankets, rubber rollers and metal cylinders are traditionally petroleum-based products including naphtha, mineral content alcohols, methanol and toluene, xylene, methanol, MEK (methyl ethyl ketone), glycol ether, TCA (trichloroethane), etc. (NSW, 2006).

\section{VOC and HAP Emissions in Printing Performed with Water and Solvent Based Inks}

Pigments and binders are non-volatile solid components of the ink mixture. However, solvent-based inks include alcohols and esters as volatile organic components that have the concentration ranging from $50 \%$ and $70 \%$ (US EPA, 1980; Saad, 2007). The amount of solvent retained by flexo, gravure and screen-printed products is $3-4 \%$ of total ink solvent used. The solvent in the printed ink content, except for the one held by the printed material evaporates in its own environment after the printing process (Hettige, Mahanama, \& Dissanyake, 2001). While the majority of this solvent is released to the air, the remaining part continues to blend into the environment for a long time right after the application albeit at a diminishing pace (Özçelik, 2006). VOCs contribute to atmospheric photochemical reactions. VOCs mean organic solvents and diluters releasing to the atmosphere during the 
printing process in practice. Around $75-90 \%$ of the emissions of volatile organic compounds releasing from ink dryers exhaust into the nature, depend upon the printing speed, frequency of printing hesitation, ink solvent compound, printed product, design and efficiency of drying systems. Most of the emissions in the production environments are caused by solvent evaporation in the ink tank and the solvent evaporation on printed product in the drying systems between uncontrolled printing units. The amount of leakage evaporation depends on volatility of the solvent, temperature in ink tank and in the environment, design and efficiency of dryer, the time and frequency of printing machine's pause and restart (Jones, 2004). The amounts of potential VOC or the air-pollutant emissions are equal to the amount of solvent used during the printing process (US EPA, 1982).

The solvents widely used in printing industry are ethanol, toluene, ethyl acetate, isopropanol, n-propanol, hexane, toluene-xylene-naphtha mixture, methyl ethyl ketone, isopropyl acetate, n-propyl acetate, glycols, glycol ethers and water (Özçelik, 2006; Rösch et al., 2014). Organic solvent-contain heat-set web offset, flexographic, gravure, non-impact (digital) and screen printing inks are all possible sources of VOCs. While solvent based inks are widely used in flexo, gravure and screen-printing systems, the use of water-based inks is limited (Özçelik, 2006). Liquid inks used in flexo and gravure printing have pretty volatile solvents. (e.g. aliphatic and aromatic hydrocarbons, alcohols, ketones and esters) and they can dry rapidly due to their volatility; these inks put VOCs into the air during the printing process (Saad, 2007). The use of water-based inks as emission reduction alternative is limited, because some non-absorbent substrate surfaces with high surface energy are not printable due to the difficulty of adhesion and evaporation (Jones, 2004; Sensorex, 2017). Nevertheless, use of water-based inks is encouraged due to some environmental concerns (Aydemir, 2016).

During the flexo and gravure printing process, the raw ink is diluted with solvent. In these systems, the ink mixture is transferred constantly to the printing material surface through the plate cylinders. After the first colour is printed, the printing material moves across the heat-set air dryer to evaporate the volatile solvent in the ink. Thus, it is provided that the first printed colour be dried by vaporizing the volatile organic compounds in the ink. This process is repeated for all other colour printing units (US EPA, 1980). As a result of the drying process, VOCs recirculating in dryer are released into the air without any processing (filter or afterburner) and they become an important source of environmental pollution (Saad, 2007).

\section{VOC and HAP Emissions in Printing Performed with Oil-Based Ink}

Production of printing ink releases pigment extenders and potential VOC emissions into the atmosphere. The materials containing VOC and HAP used in sheet-fed offset printing method are isopropyl alcohol or dampening solutions, ink, upper varnish, lacquer and cleaners of other printing compounds, blanket and roller washers, ink oils and coatings.

Isopropyl alcohol (IPA) is traditionally used to control the physical features of dampening solution. The use of flammable and toxic isopropyl alcohol in offset printing dampening solution at the rate of 8-10 percent is the primary cause of VOC emissions polluting the working environment (Rossitza, 2015; Government of Canada, 2016).

No retention or release factor for VOC and HAP in other materials used in dampening solutions, blanket washers, coatings or sheet-fed offset printing processes has been introduced. Thus, emissions of these materials are considered to be released into the atmosphere (US EPA, 1982). Changing to waterless offset (dry offset) eliminates the VOC emissions caused by IPA. However, this requires a large initial investment.

The inks used in heat-set web offset printing contain high boiling mineral oils. During the process where these inks are dried in coated paper surface, solvent oils are evaporated at the temperature of $120-150^{\circ} \mathrm{C}$. However, the gases formed during the process of evaporating the mineral oils are released into the nature and increases air pollution.

In UV curing, printing stability and printing quality are at a good level. The reason is that the chemical reaction does not start until the energy is applied during the drying process. Therefore, there is no VOC problem (Argent, 2008). The lack of solvent in UV ink, turns the UV curing into an attractive option in cases where the solvent emissions should be reduced (Brilliant Universal Limited, 2020).

\section{VOC and HAP Emissions in Post-Press Processes}

Materials containing VOC and HAP used in postpress processes are adhesives, binding and finishing equipment and glues. Using water-based adhesives for binding and self-adhesive labels will reduce the negative impact on the environment. 


\section{The Use and Storage of the Solvents}

National and international legislations impose obligations on both producers and the users of a solvent.

Solvents should be labelled in accordance with the provisions of the regulations. The adhesive should include producer information, name and formula of the chemical, trade name of the product, intended usage area and hazard symbols.

Solvents should be sealed-packaged where there will not be any leakage, spreading, etc. during normal storage and transportation processes. The shape and label of the package should not look like the packages of foodstuffs in terms of general view and scope.

Solvents should be stored in a manner that they will not damage the environment and human health. Necessary measures should be taken so that these materials will not be misused by irresponsible individuals.

\section{Issues to be Considered During the Use of Solvent and Material Containing Solvent}

Solvents may have the feature of 'hazardous chemical' according to the feature of chemical materials they contain, and they may also have the feature of hazardous waste as a result of its usage. While a specific part of the solvents expired in printing is released to the atmosphere as air emissions through ventilation and process pipes, other specific part evaporates and vanishes into the air. As in other industrial facilities, precautions that will ensure an ideal working environment in accordance with Occupational Health and Safety Legislation should be taken by measuring the degree of solvent in the environment. The employees having health problems due to the working in the printing companies with solvents should be prevented. For this purpose, the following risk control measures should be taken in printing facilities:

- Personal protective equipment should be used in accordance with Occupational Health and Safety Legislation.

- Unnecessary use of halogenated solvent should be avoided.

- Water based product without solvent should be preferred.

- Multipurpose solvent use should be preferred rather than using separate solvent for each process.

- Solvents or products containing solvent should be used in well-ventilated zones.
- Attention should be paid to warning information and safety recommendation on the labels.

- Solvents or products containing solvent should not be thrown away into the sewer.

- Contact of solvents or any product containing solvent with the skin should be avoided and protective equipment should be used when necessary.

- Solvent should never be used to remove the materials such as paint, oil, etc. on the skin.

- Solvents should be preserved in closed areas and the leak-proof containers should be used for the wastes of solvent.

- Unless necessary and suitable ventilation is available in closed areas, materials containing solvents should not be used and appropriate masks should be used in these areas when necessary.

\section{Conclusion}

Printing ink manufacture results in the potential emissions of VOCs and pigment/extender dusts to atmosphere. Therefore, it is a technical imperative to reduce VOCs in petroleum-based printing inks to meet environmental regulations without sacrificing functional properties. Reducing VOC's is a technical obligation. In this context, mineral oils and hydrocarbon solvents used in production of cold-set, heat-set and sheet-fed ink should be minimized or they should be replaced with the solvents with low aromatic content (linseed-soybean oil-based, etc), if possible. The emissions of volatile solvents used in production of flexo and gravure printing inks, should be kept at minimum by using fully enclosed systems. Emissions of volatile solvents used in the manufacture of flexographic and gravure inks are kept to a minimum by use of fully enclosed or covered systems. Non-recyclable liquid wastes produced by ink manufacturers and printing companies should not be discharged to the drainage, they should be moved away from the environment by accredited waste management companies. Process water should be purified and recycled, and the precious chemicals and compounds should be regained.

Since not any ink technology or printing process offer a universal environmental solution, most appropriate production and ink option should be identified by taking the factors such as substrate absorptivity, source of energy, energy consumption and carbon footprint into consideration. Excessive ink consumption will certainly have adverse effects on the environment, because of higher consumption of energy resources. Therefore, environmental sustainability of printing can be achieved by keeping ink consumption at an optimum level in the printing production process. 
There are many ways to prevent the VOC emissions. Usually, these require changes in raw material types or production process. When selecting the raw material, the requirements of special environmental protection legislation such as Packaging and Packaging Waste Directive and Restrictions on Hazardous Substances Directive for the printed materials and products should be taken into consideration. Disposal/Replacement and process modification is a control step that should be considered in each workflow if there is a solvent risk. Closed loops that does not produce any waste and preserves precious raw materials should be designed. VOC containing chemicals can in many cases be substituted with other agents that have lower environmentally and health effects. The option of not using solvent or replacing it with harmless or less harmful solvent should be considered. Water and plant-based systems should be preferred to a certain extent if possible. Thus, the amount of VOC released into the atmosphere and hazardous waste will be less.

Various emission control equipment and techniques can be used to control VOC vapours. For a modern printing facility, air pollution control system consists of two categories: recovery of evaporative solvent or disposal of the solvent. The solvents should be disposed according to the waste management hierarchy. Solvent recovery is the only available method controlling VOC emissions coming from printing machines. Solvent recovered with the recycling system should be directly reused in printing process. For instance, in gravure inks, solvents can be subjected to recovery phase above 98 percent and recovered solvent can be reused in ink production.

European REACH Regulation (EC) regarding the use of certain chemicals and volatile organic solvents should be taken into consideration in terms of human health and environmental effects. Certain activities that may damage the environment and human health in printing companies, should be controlled. The employees of printing house should be trained about keeping the use of solvents at minimum and producing without causing pollution or problems in the environment.

In production line, the equipment reducing ink, dampening water solvents, cleansing solvents and other contaminant emissions or applicable regulations should be taken into consideration.

There are two ways of reducing VOC emissions from the dampening systems: IPA can be replaced with alcohol substitutes, or the degree of evaporation can be reduced. Changing IPA to glycol- or glycol-ether based alternatives can reduce VOC emissions. In addition, the evaporation of IPA can be reduced by refrigerating the dampening solution. Similarly, solvent evaporation can be slowed down by using cooling systems in flexo and gravure printing ink tanks.
Planning should be carried out in order to keep washing needs at minimum and efficient blanket washing systems that use the least amount of blanket washing solvent should be preferred. An important retention factor in determination of VOC and HAP emissions are low vapour pressure cleaning solutions used with swabs. Swabs should be preserved in a closed container when not in use. They should be disposed by a licensed effluent treatment plant after they are used.

\section{References}

Argent, D. (2008) Drying Part 3: Paste Inks. Available from: https://www.pffc-online.com/ print/inks/6097-drying-part-paste-0401 [Accessed: 29th February 2020].

Aydemir, C. \& Özakhun, C. (2014) Printing Materials Science. Istanbul, Marmara University Publisher.

Aydemir, C. (2016) A study on the printability properties of alkali-sized recycled papers. Science and Engineering of Composite Materials. 23 (5), 565 - 571. Available from: doi: 10.1515/secm-2013-0266

Aydemir, C., Yenidoğan, S., Karademir, A. \& Arman Kandirmaz, E. (2018) The Examination of Vegetable- and Mineral Oil-Based Inks' Effects On Print Quality Green Printing Effects With Different Oils. Journal of Applied Biomaterials \& Functional Materials. 16 (3), 137-143. Available from: doi: 10.1177/2280800018764761

Aydemir, C., Karademir, A., Imamoğlu, S., Altay, B. N., Fleming, P. D. \& Tutak, D. (2019) Investigation of the evolution of hydrophobicity and wettability of paper in multi-color printing process. Cellulose Chemistry and Technology. 53 (7-8), 787-794. Available from: doi: 10.35812/CelluloseChemTechnol.2019.53.77

Aydemir, C., Yenidoğan, S. \& Özsoy; S. A. (2020) Effects of ink consumption on print quality on coated cellulose-based paper surfaces. Cellulose Chemistry and Technology. 54 (1-2), 89-94. Available from: doi: 10.35812/CelluloseChemTechnol.2020.54.10

Blue Angel, The German Ecolabel. (2020) Print Houses and Printed Matters. Available from: https://www.blauer-engel.de/en/products/ paper-printing/print-houses-and-printed-matters/prospekte [Accessed: 20th March 2020].

Brilliant Universal Limited (2020) UV Curing Technology. Available from: http://www.bul.com.hk/bul/en/technologies/uv_curing [Accessed: 11th March 2020].

EuPIA (2013) Environmental Impact of Printing Inks, Information Note. Available from: https://www. eupia.org/fileadmin/FilesAndTradExtx_edm/201303-05_EuPIA_Environmental_Impact of_Printing_Inks_01.pdf [Accessed: 13th January 2020]. Government of Canada (2016) Printing Industry and Volatile Organic Compounds, Available from: https:// www.canada.ca/en/environment-climate-change/ services/managing-pollution/sources-industry/vol- 
atile-organic-compounds-consumer-commercial/ printing.html [Accessed: 23th February 2020].

Hermann, C. (2014) Ink's Environmental Footprint. Available from: https://blog.drupa.com/en/inks-environmental-footprint-2/ [Accessed: 23th January 2020].

Hettige, C., Mahanama, K. R. R. \& Dissanyake, D. P. (2001) Cyclohexane Oxidation and Carbon Deposition Over Metal Oxides Catalysts. Chemosphere. 43 (8), 1079-1083. Available from: doi: 10.1016/S0045-6535(00)00195-8

IFC (2007) Environmental, Health, and Safety Guidelines for Printing. Available from: https://www. ifc.org/wps/wcm/connect/db5f5467-a530-417f97fb-65b76fabc32a/Final\%2B-\%2BPrinting.pdf?MOD=AJPERES\&CVID=jqeshai\&id=1323152584582 [Accessed: 29th December 2019].

Inglezakis V. J. \& Poulopoulos S G. (2006) Air and Water Pollution. Adsorption, Ion Exchange and Catalysis. Design of Operations and Environmental Applications. Amsterdam, Netherlands, Elsevier Science, pp. 1-30.

Jones G. A. (2004) Determining VOC/HAP Emissions from Sheetfed Offset Lithographic Printing Operations. Printers' National Environmental Assistance Center (PNEAC). Available from: hdl.handle. net/2142/104657 [Accessed: 19th February 2020].

Khan, F. I. \& Ghoshal A. Kr. (2000) Removal of Volatile Organic Compounds from Polluted Air. Journal of Loss Prevention in the Process Industries. 13 (6), 527-545. Available from: doi: 10.1016/S0950-4230(00)00007-3

Leung, D. Y. C. (2015) Outdoor-indoor air pollution in urban environment: challenges and opportunity. Frontiers in Environmental Science. 2 (69), 1-7. Available from: doi: 10.3389/fenvs.2014.00069 NSW (2006) Environmental Action for the Printing Industry, Sydney South, Australia, Department of Environment and Conservation (NSW). Available from: https://www.epa.nsw.gov.au/ /media/EPA/ Corporate\%20Site/resources/clm/2006357PrintIndustry.ashx [Accessed: 14th February 2020].

Okubo, M. \& Kuwahara, T. (2020) Prospects for marine diesel engine emission control. Chapter 5. New Technologies for Emission Control in Marine Diesel Engines. Amsterdam, Netherlands, Elsevier Science, pp. 211-266. Available from: doi: 10.1016/B978-0-12-812307-2.00005-5

Özçelik, T. G. (2006) Catalytic Combustion of VOC's in Printing Units of Packaging Industry. PhD thesis. Ege University Graduate School of Applied and Natural Sciences, İzmir. Available from: https:// acikerisim.ege.edu.tr/xmlui/handle/11454/2615 [Accessed: 11th September 2019].

Robert, T. (2015) "Green Ink in All Colors" - Printing Ink From Renewable Resources. Progress in Organic Coatings. 78 (11), 287-292. Available from: doi: 10.1016/j.porgcoat.2014.08.007

Rossitza, S. (2015) Offset Printing without Isopropyl Alcohol in Damping Solution. Energy Procedia. 74 (76), 690 - 698. Available from: doi: 10.1016/j.egypro.2015.07.804

Rösch, C., Kohajda, T., Röder, S., Bergen, M. \& Schlink, U. (2014) Relationship between sources and patterns of VOCs in indoor air. Atmospheric Pollution Research. 5 (1), 129-137. Available from: doi: 10.5094/APR.2014.016

Saad, A. A. E. R. E. (2007) Environmental Pollution Reduction by Using VOC-Free Water-Based Gravure Inks and Drying Them With A New Drying System Based on Dielectric Heating. PhD thesis. Bergische Universität Wuppertal. Available from: https:// books.google.rs/books/about/Environmental_Pollution_Reduction_by_Usi.html?id=WoVHvwEACAAJ\&redir_esc=y [Accessed: 28th January 2020].

Sensorex. (2017) How pH Monitoring Can Improve Print and Color Quality of Water-Based Ink. Available from: https://sensorex.com/blog/2017/04/25/ph-monitoring-water-based-inks/ [Accessed: 09th January 2020].

Svendsen, K. \& Rognes K. S. (2000) Exposure to organic solvents in the offset printing industry in Norway. The Annals of Occupational Hygiene. 44 (2), 119-124. Available from: doi: doi.org/10.1093/ annhyg/44.2.119 [Accessed: 23th December 2019].

US EPA (1980) Publication Rotogravure Printing Background Information for Proposed Standards, Draft EIS, EPA-450/3-80-037a. North Carolina.

US EPA (1982) Publication Rotogravure Printing - Background Information for Promulgated Standards, Final EIS, EPA-450/3-80-031b. North Carolina.

US EPA (2018) Volatile Organic Compounds Emissions, Report on the Environment. Available from: https://cfpub.epa.gov/roe/indicator. cfm?i=23 [Accessed: 15th October 2019].

Viegas, S. (2011) Occupational health. In: Brebbia, C.A., Eglite, M., Knets, I., Miftahof, R. \& Popov, V. (Eds.) Occupational exposure to volatile organic compounds in the Portuguese printing industry. Section 6. Environmental Health and Biomedicine. Southampton, United Kindgdom, WIT Press, pp. 233-240. Available from: doi: 10.2495/ EHR110211 [Accessed: 10th October 2019].

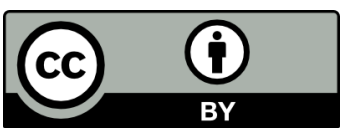

(C) 2020 Authors. Published by the University of Novi Sad, Faculty of Technical Sciences, Department of Graphic Engineering and Design. This article is an open access article distributed under the terms and conditions of the Creative Commons Attribution license 3.0 Serbia (http://creativecommons.org/licenses/by/3.0/rs/). 